\title{
Espécies de Parapsaenythia de Costa Rica descritas por Friese (Hymenoptera, Apoidea) ${ }^{1}$
}

\author{
Jesus S. Moure ${ }^{2}$
}

\begin{abstract}
Parapsaenythia species from Costa Rica described by Friese. FRIESE (1916) described Parapsaenythia flavescens, changing the name to $P$. argentina. This species is a Colletidae, Paracolletini and belongs in Eulonchopria Brèthes, 1909, and a new combination Eulonchopria flavescens (Friese, 1916) is proposed. The second species apparently was not described: it is a Panurgini and here described as Friesina carinulata gen.n. and sp.n.. At Berlin Museum Psaenythia bernardinensis syn.n., decribed by STRAND (1910), from Paraguay, is the male of Eulonchropia paraguayensis Brèthes, 1909, syn.n..

KEY WORDS. Eulonchopria, Paracolletini, Friesina, Panurgini, Costa Rica, Psaenythia bernardinensis, Eulonchopria psaenythiodes
\end{abstract}

Friese marcou em sua coleção, atualmente no Naturkunde Museum der Humboldt Universität, Berlin, como pertencentes ao gênero Parapsaenythia Friese, 1908, duas espécies diferentes provenientes da Costa Rica a que deu os nomes de flavescens e carinulata, chegando a descrever a primeira em 1916, porém deixando de publicar a segunda. Tive oportunidade de estudar esses exemplares e verifiquei que nenhuma delas pertence a esse gênero aparentemente restrito à América do Sul.

A primeira, publicada como Parapsaenythia flavescens Friese, 1916, é na realidade um Colletidae, Paracolletinae, do gênero Eulonchopria Brèthes, 1909 e a segunda representa um Panurginae, aparentemente um gênero e espécie novos, que a seguir descrevo em homenagem a Friese como Friesina carinulata.

\section{Eulonchopria flavescens (Friese, 1916) comb.n.}

Parapsaenythia flavescens Friese, 1916: 301.

Holótipo fêmea de San José, Costa Rica, no Naturkunde Museum der Humboldt Universität, Berlin (Gaveta: 523/10). Tem a perna posterior esquerda colada.

Pertence ao gênero Eulonchopria descrito por BRÈTHES (1909) para Eulonchopria psaenythioides do Paraguai, e que pelo nome específico, dá a entender que se trata de uma espécie mimética. STRAND (1910) descreveu o macho desta espécie como Psaenythia bernardinensis syn.n.. Provavelmente Strand não teve conhecimento da descrição de Brèthes saída um ano antes ao da sua publicação.

FRIESE (1921), descreveu no "Nachtrag" sobre as abelhas de Costa Rica Parapsaenythia costaricensis, sem referência clara à Parapsaenythia flavescens,

1) Contribuição número 1087 do Departamento de Zoologia, Universidade Federal do Paraná.

2) Departamento de Zoologia, Universidade Federal do Paraná. Caixa Postal 19020, 81531-990 Curitiba, Paraná, Brasil. Bolsista do CNPq. 
porém à Parapsaenythia argentina. É certamente outra espécie, de outro gênero muito diferente, com duas células submarginais ("Vorderflügel nur mit 2 Kubitalzellen [2. Kubitalquerader nicht ausgebildet]"), sem faixas amarelas nos tergos, descrevendo o abdomen como: "Abdomen runzlig punktiert, matt, mit breiten, fast glatten Segmenträndern, Segment 1 mit glatter Basis, 1-3 fast kahl, 3-4 mit gelblich befilzter Basis und Endrand (?), 6 und Endrand von 5 lang rotgelb befranst, Analplate kahl, hoch gewölbt." Não há nenhuma referência às faixas amarelas! Essa descrição também não se aplica à que abaixo descrevo.

Eulonchopria foi um gênero com caracteres excepcionais que levaram MOURE (1945) a propor para o mesmo uma subfamília, Eulonchopriinae, pela conformação extremamente característica do bordo posterior da cabeça e pelo revestimento de pequenos tufos brancos semelhando escamas. Esses caracteres se repetem exatamente no exemplar costariquenho em mãos. É possível que se trate da espécie descrita por MiCHENER (1963) como Eulonchopria oaxacana. Ao descrever essa espécie, Michener redefiniu o gênero. Posteriormente fez uma revisão das espécies e em 1989 reestudou este gênero entre os Paracolletini. Fez neste último trabalho um subgênero novo Aethalonchopria, para substituto de Apista Vachal, 1909, para o qual havia eu deixado um nome manuscrito na Coleção Vachal, quando a revisei em 1958 no Museu de Paris.

Foram tomadas as seguintes notas sobre o exemplar de Eulonchopria flavescens.

Fêmea de porte médio: comprimento total aproximado $11.83 \mathrm{~mm}$, asa anterior $8,00 \mathrm{~mm}$; largura da cabeça $3,24 \mathrm{~mm}$.

Predominantemente preta, com a cabeça projetada para trás em fino bordo, parecendo uma lâmina translúcida; as antenas e pernas pardo-ocráceas; o abdome castanho muito escuro, quase preto, com três faixas marginais amarelo-claras ocupando as depressões marginais de T1, T3 e T4, levemente bissinuadas; uma mancha amarela-borrada nas abas ventrais de T1; a placa pigidial parabolóide fracamente acuminada por uma reintrância a cada lado, pardo-ferrugínea no disco com uma pequena mancha amarela a cada lado na base, a ponta preta. A placa basitibial grande (60:40), rebordada, e com cerdas pretas grossas e curtas na superfície interna, deixando livre pequeno espaço apical. Tégulas castanho-ferrugíneas; asas amarelentas, levemente escurecidas para o ápice e bordo costal; venação e estigma amarelos, o apêndice da célula marginal escurecido.

Pilosidade muito especializada, formada por pêlos curtos branco-plumosos caracteristicos de Eulonchopria, parecidos a pequenos tufos, em certa luz, esbranquiçados. Um pouco mais longa nos esternos e principalmente a escopa do fêmur ao tarso. Concentrações maiores de pêlos no bordo do clípeo formando estreita franja $[150 \mu]$ amarelo-dourada em arco subtruncado, com algumas cerdas médias mais longas no quarto médio apical [chegando até $350 \mu$ ]; tambem na sutura escutescutelar adensadas e um pouco mais longas e mais largas que nas áreas próximas, outras contornando os lobos pronotais; mais alongadas e mais brancas na região inferior dos mesepisternos, atrás inclinadas para baixo. No propódeo no lado externo do sulco lateral que limita a área basal; amarelenta no terço apical de T5 e no T6 aos lados da placa pigidial. 
Pontuação densa, os intervalos careniformes finos com pequenas áreas mais brilhantes, um pouco irregulares no clípeo e na supraclipeal e mais fina nas genas; no mesoscuto mais regular, cada ponto com pequena pluma branca, os intervalos finos e brilhantes, no escutelo alguns intervalos maiores até cerca de 1dp, brilhantes e com micro-pontos intercalados; nos mesepisternos os intervalos reticulados e na porção anterior ao sulco preocipital, abaixo e atrás dos lobos pronotais, muito esparsos, com intervalos até 2,5dp, reticulados e multi-pontilhados; os metepistenos com carenas finas e fortes, transversais, encurtadas posteriormente abaixo dos espiráculos; essas trabéculas transversais ainda mais fortes nos flancos do propódeo até as carenas látero-posteriores; um pouco mais grossa nos cantos basais e na face posterior; na área basal com fortes trabéculas dispostas irregularmente. Nos tergos densa, um pouco mais fina que no mesoscuto, porém um pouco menor que na metade distal de T5. A placa pigidial toda finamente estriolada da base para o ápice, este claramente rebordado.

A cabeça um pouco mais larga que longa (325:300); olho um pouco mais longo que duas vezes sua largura (192:90); as genas de perfil um pouco mais estreitas que a largura do olho, estreitadas para baixo e marginadas atrás por forte carena; as distâncias interorbitais um pouco maiores que o comprimento do olho (215:235:195). Clípeo levemente abaulado, cerca de 1,65 vezes mais longo que largo, com o bordo anterior em arco subtruncado; seu comprimento cerca de 7/9 da sua distância ao ocelo médio. As fóveas faciais longas e estreitas (100:18), com o fundo relativamente liso; distância interalveolar menor que a alveolorbital e a área supraclipeal em triângulo um pouco mais elevado formando uma carena frontal terminando a dois diâmetros de ocelo antes do ocelo médio; distância interocelar menor que a ocelorbital, cerca de 3,5 vezes o diâmetro do ocelo médio e este menor que a distância ao bordo ocipital (90). A língua curta, curto-bilobada; os três primeiros artículos dos palpos (únicos restantes) com as seguintes proporções 20:12:12. O labro curtamente bituberculado. Escapo cerca de seis vezes o seu diâmetro, mais estreitado para a base, bem mais longo que a distância entre o alvéolo e o ocelo lateral; flagelo e pedicelo juntos 1,85 vezes mais longos que o escapo; os três primeiros flagelômeros na proporção de 26:16:20, bem mais curtos que $o$ diâmetro do terceiro (30).

Os outros dois exemplares, machos, ficaram registrados na coleção Friese como Parapsaenythia carinulata, cuja descrição não encontrei. Para mim constituem um gênero novo de Panurgini que lembra Pseudopanurgus. Denomino-o Friesina em memória de Friese que primeiro o estudou.

\section{Friesina gen.n.}

Espécie tipo: Friesina carinulata sp.n..

Trata-se de um Panurgini que lembra a Pseudopanurgus Cockerell, 1897.

Comparei a presente espécie com Pseudopanurgus aethiops (Cresson, 1872) tipo do gênero, e com o trabalho de MiTCHELL (1960). O carater diferencial mais pronunciado é a presença de faixas pilosas muito desenvolvidas. Em Pseudopanurgus as faixas marginais de T1-4 são deprimidas, lisas e inteiramente glabras. 


\section{Friesina carinulata sp.n.}

Figs 1-6

Comprimento total aproximado $6,7 \mathrm{~mm}$, da asa anterior $5,4 \mathrm{~mm}$; largura da cabeça 2,02 mm. (Fig. 1).

Preto, com os seguintes desenhos amarelos: um pequeno triângulo um pouco deformado no disco do clípeo (30:20), mais próximo ao bordo apical; manchas nas paroculares interiores, alongado-ellipsoides, completas até a altura média do alvéolo (Fig. 2). Uma faixa fina no bordo anterior do pronoto. As pernas ferrugíneas, nos três pares com larga estria amarela da base até quase o ápice, e pequena mancha na extremidade basal do basitarso posterior (Figs 1-3). Tégulas pardo-ocráceas; asas amarelentas.

Pilosidade branca, com poucos pêlos aos lados do clípeo inferiormente e nas genas como que umbilicada muito curta; alguns pelinhos um pouco mais longos junto aos alvéolos e também acompanhando a carena pos-ocipital. Muito densa, dando impressão de uma faixa no bordo superior do pronoto e marginando os lobos pronotais (Fig. 3); alguns pelinhos no bordo anterior e ao longo das margens laterais do mesoscuto, moderadamente densa na sutura escuto-escutelar e acompanhado a carena subalar (Fig. 5). Pelinhos eretos mal sobressaindo aos pontos areolados no mesoscuto, melhor percebidos em vista lateral; no escutelo um pouco mais longos, mais desenvolvidos passando a mais longos no metanoto; nas pernas mais longos, mais desenvolvidos nos basitarsos. Evidente nos flancos do propódeo e formando faixas marginais estreitas bastante densas em T1-4, os pêlos um pouco mais esparsos e mais longos nas margens de T5-6; outros bem mais curtos emergindo dos pontos próximos à base dos tergos, bem visíveis em certa luz; nos esternos mais finos e mais longos, plumosos.

A pontuação areolada, os intervalos fortes e elevados que mereceram o nome dado por Friese. Essas aréolas maiores e menores na cabeça, tórax e abdome, com variação no tamanho e no formato: menores em geral na cabeça [entre 20 e $60 \mu$ ], maiores no mesoscuto $[60-100 \mu]$ porém muito irregulares e as vezes vários fundidos entre si; os interespaços todos finamente careniformes, elevados, ficando os pontos em forma de fovéola (Figs 3-4); no escutelo e no metanoto as fusões de 2-4 fovéolas muito frequentes, dando às carenas separadoras um aspecto vermiculado (Fig. 5). As fovéolas geralmente maiores $(100 \mu)$ nos mesepisternos (Fig. 3), menos nas faces laterofrontais onde passam a pontos normais, bastante finos $(20 \mu)$ e alguns interespaços mais largos que os pontos; nos metepisternos fundidos de lado a lado formando trabéculas transversais. No propódeo os flancos e a face posterior com fovéolas grandes e irregulares, porém na base com uma série de fóveas maiores em pequenos paralelogramos fortemente trabeculados e alongados $(160: 100 \mu)$. Nos tergos a pontuação mais parecida à da cabeça e nos esternos bastante mais fina.

Cabeça um pouco mais larga que longa (202:175). Olho bem mais curto que duas vezes sua largura (115:78); as distâncias interorbitais superior e máxima maiores que o comprimento do olho (128:130:98), as órbitas subparalelas em cima e um pouco convergentes para baixo; as genas de perfil na sua parte mais larga superior um pouco mais estreitas que os olhos e estreitando-se para baixo, arredon- 

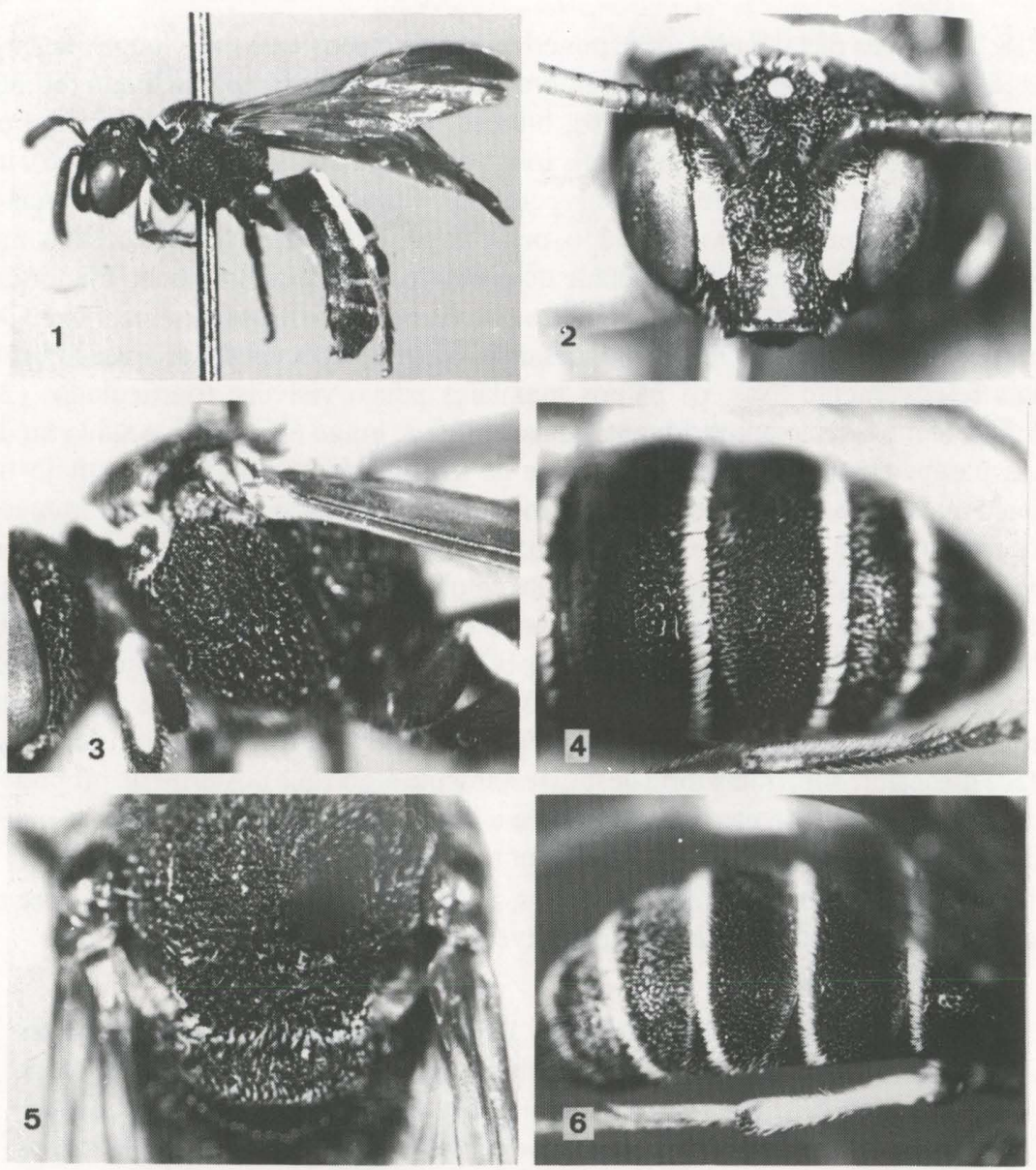

Figs 1-6. Friesina carinulata gen.n., sp.n.. (1) Vista lateral; (2) cabeça vista de frente mostrando as manchas amarelas no clipeo e nas paroculares; (3) fortíssima pontuação carenulada do mesepisterno; (4) tergos 3-6 mostrando a forte pontuação e as faixas pilosas marginais; (5) carenulado do mesoscuto e escutelo; (6) abdome fortemente clavado.

dadas, sem carena ocipital evidente. Clípeo moderadamente protuberante (cerca de 30 à frente do plano orbital) e um pouco projetado (20) alem da tangente orbital inferior, cerca de duas vezes e meia mais largo que longo e a $3 / 8$ da sua distância ao ocelo médio (Fig. 2); as placas subantenais grandes, duas vezes mais longas que largas (42:20), as suturas bem evidentes nas depressões, a área subantenal com seu limite superior indefinido entre os alvéolos, sem carena frontal definida; os alvéolos separados quase duas vezes o seu diâmetro e um pouco mais que à alvéolorbital (37:24:Ø15), e sua distância ao ocelo lateral ligeiramente maior que duas vezes a interalveolar (50); interoccelar um pouco menor que a ocelorbital, esta cerca de dois diâmetros do ocelo médio e a ocelocipital apenas a metade da ocelorbital (30:40: 
$\varnothing 18: 20)$; fóvea facial muito forte, pouco menos de cinco vezes mais longa que larga (38:8), lisa e estreitada para baixo. Labro duas vezes mais largo que longo (60:30), com a placa labral brilhante (30:20), bilobada apicalmente perdendo o brilho em direção à base. Escapo 2,5 vezes mais longo que seu diâmetro máximo (40/16), um pouco mais curto que a distância alveolocelar; flagelo e pedicelo juntos cerca de cinco vezes o comprimento do escapo; pedicelo piriforme; flagelômero basal o mais longo, obcónico, o segundo a metade do primeiro, o terceiro um pouco menor que o quarto e este igualando o seu diâmetro (20:10:14:18:Ø18). Mandíbulas fechadas e as peças bucais ocultas não sobrepassando a depressão ocupada, as áreas hipostomais relativamente lisas; os palpos maxilares pouco visíveis, triarticulados (20: 10:10). O mesoscuto anteriormente mais largo que longo (160:120), o sulco médio e as parápsides pouco destacadas entre os intervalos careniformes; escutelo um pouco mais largo que duas vezes seu comprimento (90:40); o metanoto inteiramente exposto em vista superior, um pouco mais curto que o escutelo. Asas em repouso chegando ao ápice do abdômen, com duas células submarginais a primeira recebendo m-cu ao meio; lobo jugal sobrepassando bastante o comprimento da célula anal (280:200); a placa basitibial grande (30:14), claramente rebordada. Área basal do propódeo com uma série transversal de fóveas subquadradas fortemente demarcadas pelas trabéculas agudas; a trabécula lateral mais forte entre os cantos posteriores e a face posterior, outra mais forte desde o espiráculo até a zona posterior do propódeo; o abdômen notavelmente estreitado para a base, como que clavado (Fig. 6), sem placa pigidial e E6 com o bordo posterior recortado em V.

O holótipo e um parátipo, machos, S. José, Costa Rica, na coleção Friese no Naturkunde Museum der Humboldt Universität, Berlin.

AGRADECIMENTOS. Ao Dr. Ulrich Zeller, Diretor do Naturkunde Museum der Humboldt Universität, Berlin, pelas facilidades de trabalho da Coleção Friese, ao Dr. Franz Koch responsável pela Seção de Hymenoptera, e Sra. Annete Möhlhoff na assistência para separação do material para estudo. Ao Dr. Dieter Wittmann, da Universität Bonn, pelas facilidades de trabalho no Institut für Landwirtschaftliche Zoologie und Bienenkunde, der Universität, Bonn; e ao Dipl. Biol. Volker Mauss pelas muitas vezes que me facilitou trabalhar até tarde no Instituto. Ao Prof. Dr. Albino M. Sakakibara pelas fotografias que ilustram este trabalho.

\section{REFERÊNCIAS BIBLIOGRÁFICAS}

BrĖthes, J. 1909. Hymenoptera Paraguayensis. An. Mus. Nac. Buenos Aires 20: 210-256 (Apoidea: 342-256).

Friese, H. 1916. Zur Bienenfauna von Costa Rica (Hym.). Stett. Ent. Zeitg. 77: 287-350 [1917]. 74-89.

MichenER, C.D. 1963. The bee genus Eulonchopria. Ann. Ent. Soc. Amer. 56: 844-849.

. 1989. Classification of American Colletinae. (Hymenoptera, Apoidea).

Univ. Kansas Sci. Bull. 53: 622-703. 
Mitchell, T.B. 1960. Bees of the Eastern United States. Tech. Bull. 141, North Carolina Agr. Exp. Stat. 1: 1-538.

MoURE, J.S. 1945. Contribuição para o conhecimento dos Diphaglossinae, particularmente Ptilogossa (Hym. Apoidea). Arq. Mus. Paranaense, Curitiba, 4: $137-178$.

STRAND, E. 1910. Beiträge zur Kenntnis der Hymenopterfauna von Paraguay [VII. Apidae]. Zool. Jahrb., Abt. Syst., 29: 455-562.

Recebido em 08.X.1998; aceito em 22.VI.1999 